\title{
Fe-Mo-Sm (Iron-Molybdenum-Samarium)
}

\section{Raghavan}

Recently, an isothermal section at $500{ }^{\circ} \mathrm{C}$ was determined for this ternary system by [2010Aga], which depicts a $\mathrm{ThMn}_{12}$-type ternary compound.

\section{Binary Systems}

In the Fe-Mo phase diagram [Massalski2], the $\sigma$ phase ( $D 8_{b}$-type tetragonal) and the $R$ phase (rhombohedral) form through peritectic reactions and decompose above $1200{ }^{\circ} \mathrm{C}$. $\mathrm{Fe}_{7} \mathrm{Mo}_{6}$ (denoted $\mu ; D 8_{5}$-type rhombohedral) and $\mathrm{Fe}_{2} \mathrm{Mo}$ ( $C 14, \mathrm{MgZn}_{2}$-type hexagonal) form in the solid state. The iron-based bcc phase $\alpha$ and Mo show significant mutual solubility. The Fe-Sm phase diagram [Massalski2] has three intermediate compounds: $\mathrm{Fe}_{17} \mathrm{Sm}_{2}$ ( $\mathrm{Th}_{2} \mathrm{Zn}_{17}$-type rhombohedral), $\mathrm{Fe}_{3} \mathrm{Sm}$ ( $\mathrm{Ni}_{3} \mathrm{Pu}$-type rhombohedral) and $\mathrm{Fe}_{2} \mathrm{Sm}$ (C15, $\mathrm{MgCu}_{2}$-type cubic). The interaction between $\mathrm{Mo}$ and $\mathrm{Sm}$ is negligible in the solid and liquid states.

\section{Ternary Isothermal Section}

With starting metals of $99.95 \% \mathrm{Fe}, 99.9 \%$ Mo and 99.94\% Sm, [2010Aga] arc-melted under Ar atm a number of binary and ternary alloys. After homogenization, the alloys were given a final anneal at $500{ }^{\circ} \mathrm{C}$ and were quenched into ice-water mixture. The phase equilibria were studied with optical microscopy, x-ray powder diffraction and electron probe microanalysis. The isothermal section at $500{ }^{\circ} \mathrm{C}$ constructed by [2010Aga] is shown in Fig. 1 . The ternary compound $\tau\left(D 2_{b}, \mathrm{ThMn}_{12}\right.$-type tetragonal $)$ is present at a constant Sm content, with Mo content varying between 11 and 20 at.\%. The constant Sm content is taken here to be 7.7 at.\%, corresponding to the formula (Fe,Mo $)_{12} \mathrm{Sm}$. The lattice parameters for $\tau$ determined by [2010Aga] are: $a \sim 0.856-0.857 \mathrm{~nm}$ and $c \sim 0.477$ $0.4785 \mathrm{~nm}$.

\section{Reference}

2010Aga: F.A. Agaeva, N.I. Kaloev, I.M. Bigaeva, L.K. Esieva, and G.M. Chel'dieva, Isothermal Section of the Iron-Molybdenum-Samarium System at 773 K, Zh. Neorg. Khim., 2010, 55(2), p 294-298, in Russian; TR: Russ. J. Inorg. Chem., 2010, 55(2), p 286-290

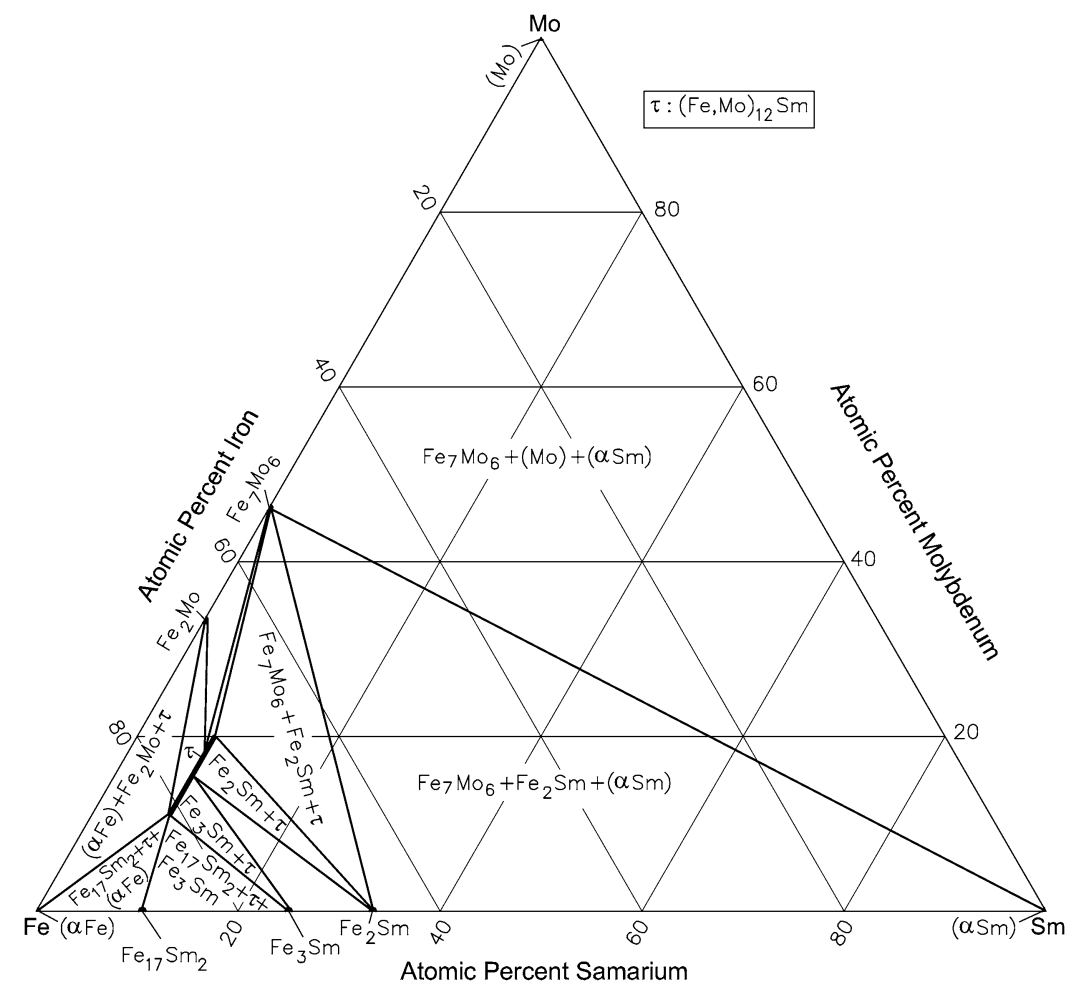

Fig. 1 Fe-Mo-Sm isothermal section at $500{ }^{\circ} \mathrm{C}$ [2010Aga]. Narrow two-phase regions are omitted 